\title{
A new method of proportioning stirrups in reinforced concrete beams*
}

\author{
by R. Taylor, B.Sc., D.I.C., A.M.I.C.E.
}

Contribution by J. M. Plowman, B.Sc., Ph.D., A.C.G.I., D.I.C., A.M.I.C.E , A.M.I.C.E.I.

(Consulting Engineer)

Mr Taylor has taken a considerable step forward in our ways of thinking about the action of shear reinforcement. That the main tensile reinforcement should add to the shear strength of a beam by dowel action seems very reasonable, but the amount of such strength must depend very greatly on the stiffness of these bars. Although the area may be the same for two sets of bars with different diameters, the actual stiffness of the sets may vary by as much as a factor of six. Perhaps Mr Taylor would enlarge a little on this.

The question of reducing the size of stirrups involves a number of problems. I have found that when the stresses in stirrups are measured, they are much less than predicted by theory and that in some cases there may actually be compression in the vertical arms where one would expect tension. This supports $\mathrm{Mr}$ Taylor's suggestion that stirrups are too big. There is another side to this, however; the horizontal arm of a stirrup which passes under the main steel acts as a binder to the concrete surrounding the main bars. Stresses in this portion may be much larger than in the vertical arms, particularly in the case of deformed bars acting as main reinforcement, because these have a very considerable bursting effect on the concrete. We must therefore look at all facets of the problem lest we weaken the beams in bending by reducing their bond strength. ${ }^{(1)}$

Reduction in stirrup diameter will result in higher stresses in the steel and therefore in greater elongation; this must result in wider cracks. Has Mr Taylor any information of a quantitative nature on this aspect of the problem?

\section{REFERENCE}

1. PLowman, J. M. Measurement of stress in concrete beam reinforcement. Proceedings of the Institution of Civil Engineers. June 1963. Vol. 25. p. 127.

\section{Reply by the author}

I am grateful to Dr Plowman for raising some interesting aspects of the behaviour of reinforced concrete beams with stirrups. It is unfortunate that these could not have been discussed more fully in the paper. Some of the points had been discussed in the more comprehensive report (reference 7 of the paper), but had to be omitted in the shortened version presented in the paper.

\footnotetext{
-Pages 171 to 181 of Magazine No. 45.
}

It cannot be claimed that the recommendations in the paper reflect perfectly the true behaviour of reinforced concrete. As Dr Plowman points out, the stiffness of the longitudinal bars will vary considerably with the diameter of the bars. In order to obtain a solution suitable for application in practice, this aspect of the problem was greatly simplified and the recommendations can be regarded as covering the "worst case ". Moreover the suggested values for $k_{1}$ and $k_{2}$ apply only to beams with reinforcement of "adequate" lateral stiffness. In the report the possibility that circumstances may arise where the longitudinal reinforcement was not sufficiently stiff was discussed, and a further qualification was suggested. The author studied this aspect of the problem in some detail and concluded that, for the great majority of reinforced concrete members, the longitudinal reinforcement will prove adequate. Only when the use of very high strength steels enables very lightly reinforced members to be constructed, for example in prestressed concrete, is such a limitation likely to be necessary.

It is gratifying to learn that Dr Plowman's experimental work supports the author's contention that less shear reinforcement could be used than is at present recommended by C.P.114. With regard to the measurement of compression in the vertical arms of stirrups, this is most likely to occur adjacent to points of application of concentrated load. In such regions stirrups may be completely unnecessary as the load can be sustained by local arching action. In the discussion of this point, it was suggested that little over-all economy would result by taking account of this since in practice the length of the region influenced by concentrated loads would be small in proportion to the total length of the beams. Usually loading will be distributed along the length of a beam, or along part of its length, through a top slab.

Incidentally the bursting effect in the case of deformed bars, and the consequent effect on bond, are automatically allowed for in the empirical evaluation of the parameters.

In the experimental investigation referred to in the paper, particular attention was paid to crack widths as it was felt that serviceability, rather than ultimate strength, would be the criterion governing the design of shear reinforcement. In all the beams designed in accordance with the recommendations, the crack widths remained fine at loads corresponding to working loads. The tests also showed that the present limitation on permissible stress in shear reinforcement is unnecessary. The use of high strength steels for stirrups had little effect either on ultimate strength or on deformations. 